\title{
THE ACCUMULATION OF RADIOACTIVE IODINE BY AMPHIOXUS
}

\author{
By I. M. Thomas \\ Department of Zoology, University of Adelaide
}

(Text-figs. I-4)

The endostyle of Amphioxus has for a long time been regarded as homologous with the subpharyngeal gland of the cyclostome ammocoete larva. This view was promulgated by Müller (I873) and by Dohrn (I886), and has been supported by many workers, for example Leach (I944). The metamorphosis of portions of the subpharyngeal gland to the thyroid gland of the adult lamprey was followed by Marine (I9I3), and uptake of radioactive iodine by certain cell elements of the subpharyngeal gland was demonstrated by Gorbman \& Creaser (I942). At the same time the latter workers failed to establish the presence of iodine in the endostyle of Amphioxus by autoradiographic techniques. Gorbman (I94I), however, showed that the ascidian Perophora annectans could accumulate radioactive iodine in its pharyngeal stolon but not in its endostyle. The part of the pharyngeal stolon involved is derived from the endostylar region of the pharynx. Recently, Sembrat (I953) has shown that endostyles of Amphioxus implanted into larval axolotls accelerated their metamorphosis, and concludes from this that the organs contain an 'active substance (or substances) which may evoke amphibian metamorphosis similarly to the active hormone of the thyroid gland. It is probable that the substance is not identical with thyroxin which may be inferred from the fact that the endostyle of Branchiostoma does not accumulate radioactive iodine (Gorbman \& Creaser, I942) as well as from its different and tolerably little efficacious influence on the amphibian metamorphosis as compared with typical metamorphic symptoms induced by the thyroid gland.' The work about to be described has demonstrated the presence of iodine in the endostyle, and suggests, further, that it is present in the form of a 'thyroid hormone-like' substance, thereby supporting Sembrat's general conclusion.

This work was done at the Laboratory of the Marine Biological Association at Plymouth. The author's thanks are due to the Director for making table space and equipment available and to the staff for many kindnesses. His thanks are especially due to Dr D. B. Carlisle for healthy criticism and comment on the work throughout its progress. Miss E. A. Robson of the Zoology Department of the University of Cambridge has assisted greatly with the photographing of the autoradiographs. 


\section{MATERIAL AND MethodS}

Amphioxus (Branchiostoma) lanceolatus (Pallas) used in this work were dredged from the Eddystone Grounds off Plymouth. They were kept in circulating sea water in their native shell gravel at the Laboratory of the Marine Biological Association at Plymouth, and maintained thus for at least I week, usually several weeks, before being subjected to treatment with radioactive iodine. In all the experiments to be described, carrier-free ${ }^{131} \mathrm{I}$ (as sodium iodide) was used at a concentration of $2 \mu \mathrm{c} / \mathrm{ml}$. for $\mathrm{I}_{5}-\mathrm{I} 7 \mathrm{~h}$, at temperatures between 5 and $10^{\circ} \mathrm{C}$. The animals were fixed in Bouin-in-seawater, washed thoroughly to remove excess radioactive material, dehydrated, embedded in paraffin wax and sectioned at Io $\mu$. Sections were mounted on gelatinized slides according to the technique of Doniach \& Pelc (I950), dried, washed in xylol to remove the wax, hydrated and covered with Kodak Autoradiographic Stripping Emulsion. The normal exposure time was I4 days. Slides were developed in Kodak D I $9 b$ developer, fixed and washed in the usual way. Some slides were stained, either with haemalum or Ehrlich's haematoxylin through the gelatin layer of the emulsion. D.P.X. was used as a mounting medium.

\section{EXPERIMENTAL RESULTS}

No uptake of ${ }^{131}$ I has been noted in the prepharyngeal part of the body, in the velum or in the peripharyngeal bands. In the endostyle two longitudinal bands of activity appear, extending from within a millimetre of its anterior extremity to its posterior extremity. In transverse sections they are seen to be situated near the periphery of and slightly lateral to the lateral series of mucous glands (Fig. I). The two median series of mucous glands show no activity at all. In some sections of the endostyle, these peripheral centres can be seen to consist of two regions, one of which is fairly compact and flattened, outside, but closely applied to its wall, while the other is more diffuse and lies immediately inside the endostylar wall. The two regions are connected by a 'neck' which lies within the cell walls (Fig. I). The outer region may be extended along the surface of the endostyle laterally on to the lowest gill bar. This activity is undoubtedly associated with mucus secreted by the lateral mucous glands. The inner region, immediately inside the cell walls of the endostyle, is slightly lateral to the lateral mucous glands. In some sections (Fig. 2) several spots of activity can be seen within the lateral mucous glands, near their bases and their borders with the layer of non-mucous cells which separate them from the median mucous glands.

Radio-activity in the secreted mucus can frequently be traced, especially in the posterior part of the pharynx, up the pharyngeal wall and into the epipharyngeal groove. From thence it can be followed backwards into the oesophagus, the mid-gut (Fig. 3) and the hind-gut. The radioactive mucus does not, however, form a continuous cord throughout the length of the gut, 
but appears in smaller or larger isolated patches. Food particles in the gut, too, having taken up some of the ${ }^{131} \mathrm{I}$, often form autoradiographic images. No radioactivity either in mucus or in food particles has been found in the lumen of the mid-gut diverticulum.

Radioactive iodine has also been located in the walls of the alimentary canal. The oesophagus may show very slight traces of uptake, but in the midgut, mid-gut diverticulum and hind-gut, uptake is much stronger, though

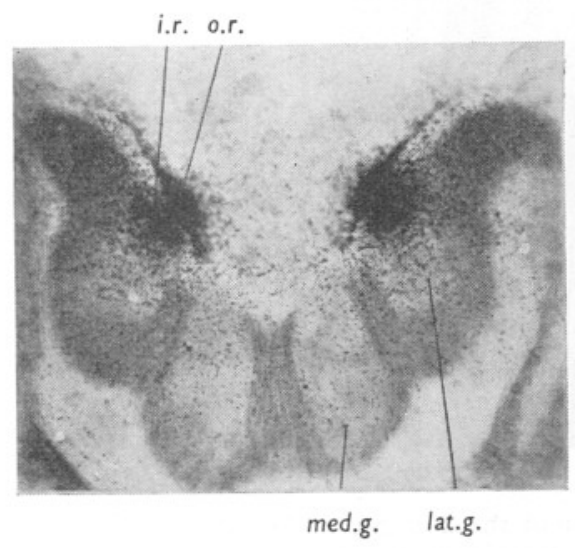

Fig. I.

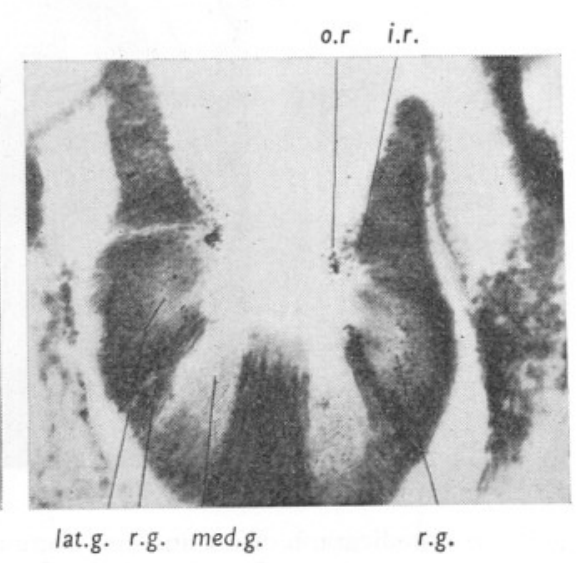

Fig. 2.

Fig. I. Autoradiograph of a transverse section of the endostyle of Amphioxus stained with haemalum; $\times 300$. lat.g, lateral mucous gland; med.g., median mucous gland; o.r., outer region of iodine uptake; i.r., inner region of iodine uptake.

Fig. 2. Autoradiograph of transverse section of the endostyle of Amphioxus stained with Ehrlich's haematoxylin; $\times 300$. r.g., iodine uptake in body of lateral mucous gland; lat.g., lateral mucous gland; med.g., median mucous gland; o.r., outer region of iodine uptake: i.r., inner region of iodine uptake.

never as intense as it is in the endostyle. In the wall of the mid-gut (Fig. 3) and hind-gut it forms a fairly well-defined band near the lumen but separated from the luminar wall by a clear space. This band, in control specimens not treated with ${ }^{131} \mathrm{I}$, is frequently pigmented yellow or brown and may contain food particles. In the mid-gut diverticulum (Fig. 4) radioactivity in treated specimens is confined to the walls and is found throughout the length of the organ, though less strongly in the anterior part. Within the cells it is distributed mainly in their distal halves. In the ventral wall the activity tends to be concentrated in the middle, and near the distal border of each cell, but in the lateral and dorsal walls it is more evenly distributed, with a slight concentration near the distal border. The reason for the accumulation of iodine in the diverticulum is obscure, unless it is either associated with the mucus of that organ or unless the diverticulum is an additional region for assimilation of the 


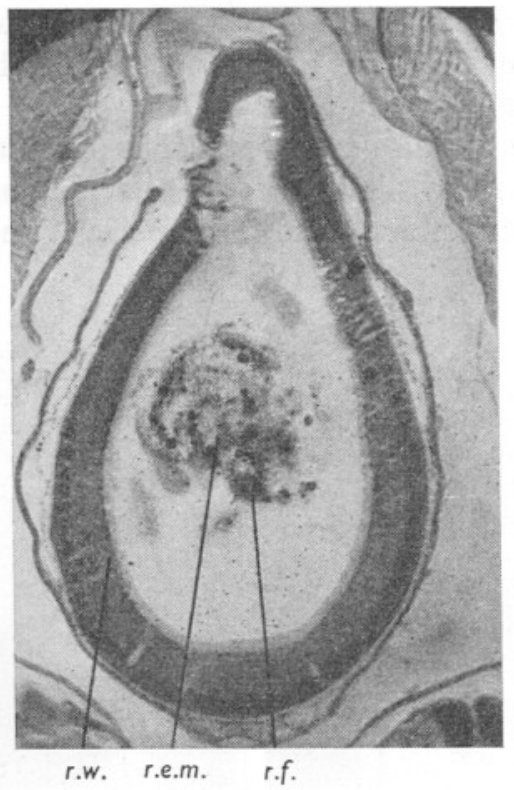

Fig. 3. Autoradiograph of a transverse section of the mid-gut of Amphioxus stained with haemalum; $\times 60$. r.f., radioactive iodine associated with food particle; r.e.m., radioactive iodine associated with endostylar mucus; r.w., radioactive iodine in wall of mid-gut.

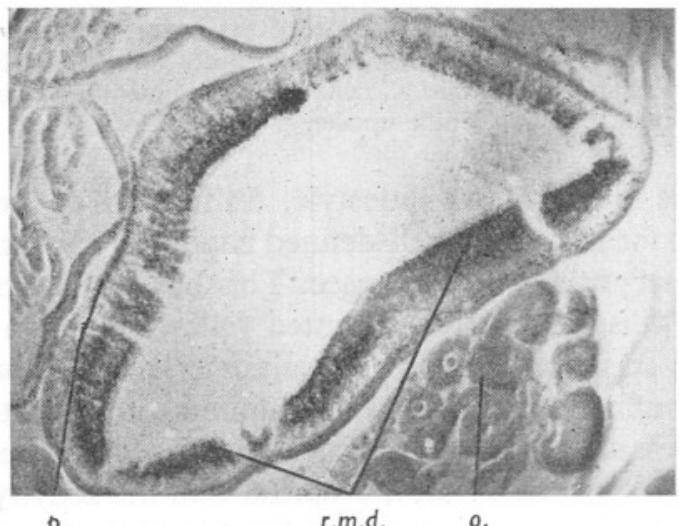

p.

0.

Fig. 4. Autoradiograph of a transverse section of the mid-gut diverticulum of Amphioxus unstained; $\times 84$. r.m.d., radioactive iodine in wall of mid-gut diverticulum; o., ovary; p., pigment granules in basal membrane of mid-gut diverticulum. 
element. If the latter supposition is true, the iodine must be assimilated directly from the sea water as, according to Barrington (I937), very few food particles find their way into the diverticulum, and those which do are usually quickly swept out again by strong ciliary currents.

A further region of the body where iodine uptake has been observed is in the ventral epithelium of the body wall between the metapleural folds and occasionally extending on to the folds themselves. Here radioactivity is weak and diffuse though it is confined within the limits of the epidermal cells. Van Weel (1937) has observed that cells in this region may have an excretory function. Carbon and melanin particles with which he fed the animals were taken up by amoebocytes in the region of the gut, and then carried by these cells through the blood stream or the coelome to the ventral body wall and deposited in the epithelium or in its underlying connective tissue. From here they were presumably released from the body. The radioactivity in this region is limited to the epithelium. None has been observed in the connective tissue in the vicinity.

\section{Effect of Goitrogens on the Distribution of Radioactive Iodine}

The most obvious centre of radioactivity in ${ }^{131} \mathrm{I}$-treated animals is in the mucus of the lateral mucous glands of the endostyle. The possibility of its being merely adsorbed as inorganic iodine on to the mucus was considered, and to check this point specimens were treated with thiourea or thiouracil simultaneously with their treatment with ${ }^{131}$ I. Thiourea was used in a concentration of $0.01 \%$ and thiouracil in a concentration of $0.04 \%$. In the higher vertebrates these and some other similar substances are known to inhibit the formation of the thyroid hormone.

In the concentrations used, thiourea and thiouracil were found to be in no way detrimental to the animals in the period of $\mathrm{I} 5-\mathrm{I} 7 \mathrm{~h}$ during which they were subjected to it. Both goitrogens had the same effect. In animals so treated, no radioactivity appeared in the endostyle, in the mucus in the lumen of the gut or in the ventral epithelium. It was still apparent, however, in food particles in the gut and in the walls of the mid-gut, the mid-gut diverticulum and the hind-gut. Its distribution in these organs was the same as in control specimens without goitrogens.

\section{Discussion AND CoNCLUSIONS}

Experiments with goitrogens indicate that the sites for assimilation of iodine are in the walls of the mid-gut, the hind-gut and possibly the mid-gut diverticulum. Here it might be taken in either directly from the water in the gut or in association with food particles as intracellular digestion has been postulated by Barrington (1937) and others. Barrington also assumes, as the result of feeding experiments with minute particles of gold, carmine and indian ink, 
the transference of food particles by the blood stream from the gut to the diverticulum. Iodine might be transferred in the same way. The volume of sea water which passes into the gut is probably small, and as the mucus in the gut of animals treated with goitrogens appears to be free of iodine it follows that most of the iodine entering the gut wall does so in association with food particles. In higher vertebrates iodine taken in through the gut walls is transferred by the blood stream to the thyroid gland, so it is reasonable to assume a similar transference from the gut to the endostyle in Amphioxus. This view is supported by the experiments with goitrogens which inhibit its appearance in the endostyle but which do not interfere with its occurrence in the gut wall.

In the endostyle 'fixation' of the iodine occurs in the lateral mucous glands near their inner borders and their bases (Fig. 2), to form a 'thyroid hormonelike substance'. This is associated with the mucus produced by these glands and its formation is prevented by goitrogens. This substance is then transferred to the periphery of the gland and secreted with the mucus. At this point, then, the iodine would be most concentrated, as is apparent from the autoradiographic images. The mucus, once secreted, would become diluted by imbibition of water. No function can at present be ascribed to this hypothetical 'thyroid hormone-like substance', though it may be significant that Amphioxus undergoes a marked metamorphosis involving alteration from a very assymmetrical larva to an externally symmetrical adult. All the specimens of Amphioxus studied have been fully adult and sexually mature. No work has yet been done on larval forms.

The absence of iodine in the ventral epithelium of specimens treated with goitrogens suggests that the iodine normally located in those cells is derived from iodine 'fixed' in the endostyle. Van Weel (1937) has described the accumulation of excretory material in the ventral epithelium, and assumes that waste food matter can be disposed of by this means. Unless the radioactive iodine remained attached to food particles throughout the digestive processes it is difficult to account for the iodine associated with food appearing in the ventral epithelium. The concentration of ${ }^{131} \mathrm{I}$ used in these experiments $(2 \mu \mathrm{c} / \mathrm{ml}$.) is low, being only about one-twentieth the concentration of the stable isotope normally present in sea water. The animals were thus not subjected to abnormally high concentrations of iodine ( ${ }^{131} \mathrm{I}$ plus $\left.{ }^{127} \mathrm{I}\right)$ during the experiments such as might bring about the excretion of abnormally large quantities through the ventral epithelium.

In this connexion an observation made during the course of the experimental work is worthy of note. It was found that animals subjected to treatment with radioactive iodine within $24 \mathrm{~h}$ after being caught took up no detectable quantity of iodine. When kept in the circulating water of the laboratory, the amount taken up increased to reach a maximum in about 7 to Io days. Unfortunately no figures are available for the iodine content of Plymouth Laboratory circulating water, nor for Plymouth coastal waters; but 
the former value is likely to be low, and a continued sojourn in the Laboratory water might deplete Amphioxus of its iodine and make it more ready to take up ${ }^{131}$ I when that becomes available. Amphioxus has been kept alive in circulating water for more than 2 months, however, without apparent detriment. This observation might account for the failure of Gorbman \& Creaser (I942) to locate radioactive iodine in Amphioxus if they worked with freshly caught material or if their animals were kept in the laboratory in normal sea water before being subjected to iodine treatment.

Two points of interest arise from the results noted in this work. First, the association of iodine with the endostylar mucus, which, of course, passes directly into the gut, may link up with the fact that the thyroid hormone in the higher vertebrates is the only hormone which retains a high degree of effectiveness when administered orally. The secretions of the gonad and the adrenal cortex have a much reduced effectiveness when given by mouth, while the secretions of the remaining endocrine glands are quite ineffective when administered by this path.

The second point concerns the 'colloid substance' which is contained in the alveoli of the thyroid gland of vertebrates. This homogeneous, viscid fluid is the stored secretion of the gland and thus contains the bulk of the iodine present. This colloid substance is, in the author's opinion, the direct evolutionary successor to the endostylar mucus of a protochordate ancestor.

\section{SUMMARY}

The localization of iodine has been studied in Amphioxus using radioactive iodine and autoradiographic techniques. The most intense concentration was found near the lateral mucous glands of the endostyle where an iodinecontaining mucus is secreted into the pharynx. Iodine was also found in the bodies of the lateral mucous glands, in the walls of the alimentary canal and mid-gut diverticulum and in some cells of the ventral body wall. It was found associated with food particles and with mucus in the lumen of the alimentary canal but not in the lumen of the mid-gut diverticulum.

Thiourea and thiouracil inhibit the appearance of iodine in the endostyle, in mucus in the gut, and in the ventral body wall, but do not prevent its appearance in the walls of the alimentary canal and mid-gut diverticulum. The significance of these results is discussed.

\section{REFERENCES}

Barrington, E. J. W., I937. The digestive system of Amphioxus (Branchiostoma) lanceolatus. Phil. Trans., B, Vol. 228, pp. 269-3I2.

Dohrn, A., 1886. Die Thyreoidea bei Petromyzon, Amphioxus und den Tunicaten. Mitt. zool. Sta. Neapel., Bd. 6, pp. 49-92.

Doniach, I. \& PelC, S. R., I950. Autoradiographic technique. Brit. F. Radiol., Vol. 23, pp. I84-92. 
GoRbMAN, A., I94I. Identity of an iodine-storing tissue in an ascidian. Science, Vol. 94, p. I92.

Gorbman, A. \& Creaser, C. W., I942. Accumulation of radioactive iodine by the endostyle of larval lampreys, and the problem of homology of the thyroid. F. exp. Zool., Vol. 89, pp. 391-402.

Leach, W. J., I944. The archetypal position of Amphioxus and Ammocoetes and the role of endocrines in chordate evolution. Amer. Nat., Vol. 78, pp. 34I-57.

MARINE, D., I9I3. The metamorphosis of the endostyle (thyroid gland) of Ammocoetes branchialis (larval land-locked Petromyzon marinus) or Petromyzon dorsatus (Wilder). F. exp. Med., Vol. I7, pp. 379-95.

MÜLLER, W., I873. Über die Hypobranchialrinne der Tunicaten und deren Vorhandsein bei Amphioxus und den Cyclostomen. Fena. Z. Naturw., Bd. 7, pp. 327-32.

Sembrat, K., 1953. Effect of the endostyle of the lancelet (Branchiostoma lanceolatum Pall.) on the metamorphosis of axolotl. Zool. Polon., Vol. 6, Fasc. I, pp. 3-I9.

WeEL, P. B. van, 1937. Die Ernahrungsbiologie von Amphioxus lanceolatus. Pubbl. Staz. zool. Napoli, Vol. I6, pp. 22 I-72. 